\title{
Associations between branched chain amino acid levels, obesity and cardiometabolic complications
}

\author{
Bénédicte Allam-Ndoul ${ }^{1,2}$, Frédéric Guénard ${ }^{1,2}$, Véronique Garneau ${ }^{1,2}$, Olivier Barbier ${ }^{3}$, Louis Pérusse ${ }^{1,4}$ and Marie-Claude Vohl ${ }^{1,2 *}$ \\ ${ }^{1}$ Institute of Nutrition and Functional Foods, Laval University, Quebec, Canada \\ ${ }^{2}$ School of Nutrition, Laval University, Quebec, Canada \\ ${ }^{3}$ Laboratory of Molecular Pharmacology, Endocrinology and Nephrology Axis, CHU de Quebec Research Center, and Faculty of Pharmacy, Laval University, \\ Quebec, Canada \\ ${ }^{4}$ Department of Kinesiology, Laval University, Quebec, Canada
}

\begin{abstract}
Aim/hypothesis: Leucine, isoleucine and valine are branched chain amino acids (BCAA). BCAAs areamong the 9 essential amino acids and are associated with beneficial health effects. However, previous studies have reported strong associations between increased BCAA levels, obesity and metabolic diseases such as type 2 diabetes. The objective of this study is to investigate the association between plasma BCAA levels, cardiometabolic risk factors and Metabolic Syndrome (MetS) in normal versus overweight/obese subjects. Methods: Mass spectrometry-based metabolite profiling of 200 samples using the Absolute ID p180 Kit was used to compare plasma BCAA levels between overweight/obese subjects with or without MetS and normal weight subjects without MetS. Results: Overweight/obese participants irrespective of their MetS status have higher plasma BCAA levels than normal weight participants (P<0.0001). Obesity-associated MetS appears to worsen the difference with normal weight subjects. Leucine $(\mathrm{P}=0.005)$ and isoleucine $(\mathrm{P}=0.02)$ levels are correlated with HOMA-IR among obese individuals without MetS. Among obese subjects with MetSleucine levels $(\mathrm{P}=0.04)$ are correlated to HOMA-IR whereas leucine and isoleucine are correlated with plasma glucose levels. Conclusions/interpretation: BCAAs are associated with obesity and MetS. Also, these results suggest that analyzing BCAAs separately may help for a better understanding of the association between BCAAs obesity and Mets.
\end{abstract}

\begin{abstract}
Abbreviations: BCAA: Branched Chain Amino Acid; CVD: Cardio Vascular Disease; DBP: Diastolic Blood Pressure; IR: Insulin Resistance; MetS: Metabolic Syndrome; SBP: Systolic Blood Pressure; Total-C: Total Cholesterol; Tg: Triglycerides; T2D: Type 2 Diabetes; WC: Waist Circumference
\end{abstract}

\section{Introduction}

In recent years, the prevalence of metabolic syndrome (MetS) paralleled the increase in the prevalence of obesity. The MetS is characterized by the clustering of abdominal obesity, dyslipidemia, insulin resistance (IR) and hypertension [1]. These conditions are associated with chronic diseases including cardiovascular disease (CVD), type 2 diabetes (T2DM) and hypertension [2,3]. Several studies reported differences in plasma metabolite composition between obese and non-obese individuals.Specific metabolite signatures including amino acids, acylcarnitines or glycerophospholipids have been associated with obesity $[4,5]$.

Leucine, isoleucine and valine are collectively referred as BCAAs due to their shared structural features in side-chain and a common catabolic pathway [6]. They are 3 of the 9 essential amino acids and are abundant in the diet representing up to $15-25 \%$ of total protein intake [7]. BCAA-rich diets are often associated with beneficial health effects $[8,9]$. Isoleucine have hypoglycemic effects in muscles and plays a role in the depression of gluconeogenesis rat liver [7]. BCAAs also promote protein synthesis, cellular metabolism and cell growth $[10,11]$. However, despite these effects on metabolic health, several studies have indicated that increased fasting levels of circulating BCAAs are associated with poor metabolic health. For instance, Yang et al. showed a positive and significant association between plasma BCAA levels and CVD risk factors [12]. Newgard et al. reported that increased BCAA levels are associated with high risk of T2DM and IR in humans and animals [5].

Therefore, the aim of the present study was to investigate the relationship between plasma BCAA levels, obesity and MetS status.

\section{Methods}

\section{Subjects}

Men $(n=101)$ and women $(n=99)$ enrolled in the present study were aged between 18 and 55 years as previously described [13]. This study was divided into two recruitment phases: from May 2004 to December 2004 and from March 2006 to April 2007. Participants were recruited in the Quebec City metropolitan area using advertisements in

Correspondence to: Marie-Claude Vohl, Institute of Nutrition and Functional Foods (INAF), Laval University 2440 Hochelaga Blvd, Quebec, Canada, Tel: 418 656-2131, Extn: 4676; E-mail: marie-claude.vohl@fsaa.ulaval.ca

Key words: leucine, isoleucine, valine, obesity, metabolic syndrome, insulin resistance

Received: September 02, 2015; Accepted: November 11, 2015; Published: November 14, 2015 
local newspapers, radio stations, and electronic group messages sent to university and hospital employees. A socio-demographic questionnaire including questions on lifestyle habits was filled by all participants during a visit. All subjects gave their written consent to participate in the study, which has been approved by the ethics committee of Laval University.

\section{Clinical and anthropometric measurements}

BMI $\left(\mathrm{kg} / \mathrm{m}^{2}\right)$ was calculated by dividing the weight $(\mathrm{kg})$ by squared height (m). The overweight/obese group had a BMI $\geq 25 \mathrm{~kg} / \mathrm{m}^{2}$ and the normal weight group had a $\mathrm{BMI}<25 \mathrm{~kg} / \mathrm{m}^{2}$. Resting blood pressure measurements were performed after a 5 minutes rest in a sitting position. Phase I and V of Korotkoff sounds being respectively used for systolic blood pressure (SBP) and diastolic blood pressure (DBP). Individuals with MetS had at least 3 of the following five criteria: waist circumference $(\mathrm{WC})>88 \mathrm{~cm}$ for women and $102 \mathrm{~cm}$ for men, fasting plasma triglycerides (TG) $\geq 1.7 \mathrm{mmol} / \mathrm{L}$, high-density lipoprotein cholesterol (HDL-C) levels $\leq 1.03 \mathrm{mmol} / \mathrm{L}$ for men and $1.29 \mathrm{mmol} / \mathrm{L}$ for women, glucose levels $\geq 5.6 \mathrm{mmol} / \mathrm{L}$ and resting blood pressure $\geq 130 / 85 \mathrm{mmHg}$.

\section{Lipid profile}

Blood glucose was measured after a $12 \mathrm{~h}$ fast. Fasting blood samples were obtained from an antecubital vein into vacutainer tubes containing EDTA. Using the Olympus AU400e system (Plympus America Inc., Melville, N.Y., USA) total cholesterol (Total-C) and TG levels were determined from plasma and lipoprotein fractions. A precipitation of low-density lipoprotein (LDL) fraction in the infranatant with heparinmanganese chloride [14] was used to obtain the HDL-C fraction. LDL-C concentrations were estimated using the Friedewald's equation [15].

\section{Metabolite profiling}

Fasting plasma samples were obtained from 200 participants. BCAA profiling of these samples were achieved using the Absolute ID p180 Kit for mass spectrometry (Biocrates Life Sciences AG, Austria). Assay used $10 \mu \mathrm{L}$ of plasma from each subject. The concentrations of all BCAAs were reported in $\mu \mathrm{M}$.

\section{Statistical analysis}

Transformations were applied to the variables that were not normally distributed. Logarithmic transformations were performed for fasting insulin, total-C and HDL-C and an inverse transformation for TG and fasting glucose. All analyses were adjusted for age and sex except for WC which was also adjusted for BMI. Analysis of variance was used to underline the differences in metabolic characteristics between obese/overweight and normal-weight participants with or without MetS. The significance level of all analyses was set at $\mathrm{p} \leq 0.05$. The results are presented for each BCAA and for the combination of all BCAAs (leucine, isoleucine and valine). To detect correlations between each BCAA or total BCAA levels and CVD disease risk factors (WC, total-C, TG, HDL-C, LDL-C, glucose, insulin, SBP, DBP and HOMA-IR), partial Pearson correlations were used for the 3 groups (overweight/obese/+MetS, overweight/obese/-MetS, normal weight/-MetS). HOMA-IR was calculated using the following formula [Fasting glucose $(\mathrm{mmol} / \mathrm{L})] \times[$ insulin $(\mathrm{mU} / \mathrm{L})] / 22.5[16]$. All statistical analyses were performed using SAS statistical software version 9.2 (SAS Institute, Inc, Cary, NC, USA).

\section{Results}

\section{Metabolic characteristics of the population}

Descriptive characteristics of study participants are presented in Table 1. Groups were defined according to BMI and MetS status. Overweight/obese individuals with or without MetS were older than normal weight subjects. Among obese individuals, subjects with MetS were older than those without MetS. As expected, WC and fat mass increased progressively from normal weight to overweight/obese participants. The same trend was observed for fasting insulin and for SBP. The overweight/obese subjects with the MetS had a more deteriorated plasma lipid profile including increased plasma TG levels and decreased plasma HDL-C levels compared to overweight/ obese without MetS or normal weight individuals. These differences remained significant after further adjustment for the confounding effect of age. There was no significant difference between groups for plasma LDL-C levels. Normal weight individuals had a lower HOMAIR $(1.61 \pm 0.94)$ than overweight/obese with $(5.33 \pm 3.69)$ or without $(2.98 \pm 2.64)$ MetS

\section{BCAA plasma levels}

Globally, participants had higher plasma levels of valine (262.2 \pm $56.3 \mu \mathrm{M})$ than leucine $(163.3 \pm 30.8 \mu \mathrm{M})$ and isoleucine $(82.1 \pm 15.6 \mu \mathrm{M}$; Table 2). Overweight/obese individuals with MetS had higher levels of each BCAA than overweight/obese without MetS or than normal weight individuals. When analysing the combination of all BCAAs, the same trend was observed, overweight/obese group with MetS had the highest levels $(507.7 \pm 93.3 \mu \mathrm{M})$, overweight/obese participants without MetS had intermediate levels $(460.8 \pm 83.4 \mu \mathrm{M})$ and normal weight individuals had the lowest levels $(413.8 \pm 83.5 \mu \mathrm{M})$.

\section{Relation between cardiometabolic risk factors and BCAAs}

The correlation coefficients between each BCAA and CVD risk factors were computed. There was a positive correlation between WC and leucine among overweight/obese participants without MetS $(\mathrm{r}=0.37$; $\mathrm{p}=0.0008$ ) (Table 3). No association was found for overweight/obese with MetS and normal weight individuals. There was also a positive correlation between HOMA-IR index and leucine among overweight/ obese subjects without MetS ( $\mathrm{r}=0.022 ; \mathrm{p}=0.05)$. This correlation was not seen among overweight/obese with MetS and normal weight subjects. Finally, correlations between fasting glucose and leucine levels $(r=0.36 ; p=0.02)$ were observed only among overweight/obese subjects with MetS. For isoleucine, there was a positive correlation with WC for overweight/obese groups with $(\mathrm{r}=0.34 ; \mathrm{p}=0.02)$ and without MetS $(\mathrm{r}=0.31 ; \mathrm{p}=0.004)$. Isoleucine was correlated to fasting glucose levels among overweight/obese participants with MetS $(r=0.35 ; \mathrm{p}=0.02)$. For HOMA-IR index a positive correlation with isoleucine was seen among overweight/obese participants with $(\mathrm{r}=0.31 ; \mathrm{p}=0.04)$ or without $(\mathrm{r}=0.25$; $\mathrm{p}=0.02)$ MetS. No significant correlation was observed among normal weight individuals. Regarding valine, results showed that there was only one significant correlation. Among overweight/obese participants, valine was correlated with $\mathrm{WC}(\mathrm{r}=0.29 ; \mathrm{p}=0.009)$. Finally, there was a positive correlation between total BCAAs and WC among overweight/ obese individuals without MetS $(\mathrm{r}=0.35 ; \mathrm{p}=0.002)$. An association between total BCAAs and HOMA-IR index among overweight/obese subjects without MetS ( $r=0.21 ; \mathrm{p}=0.05)$ was also observed.

\section{Discussion}

BCAAs are essential amino acids. Although their beneficial effects on health have been proven, it seems that increased plasma BCAA 
Table 1. Baseline characteristics of study participants.

\begin{tabular}{|c|c|c|c|c|}
\hline & \multicolumn{2}{|c|}{ MetS- } & \multirow{2}{*}{$\begin{array}{c}\text { MetS+ } \\
\mathrm{Ov} / \mathrm{Ob}(\mathrm{n}=46)\end{array}$} & \multirow[b]{2}{*}{$\mathrm{P}^{\mathrm{x}}$} \\
\hline & NW (n=65) & $\mathrm{Ov} / \mathrm{Ob}(\mathrm{n}=83)$ & & \\
\hline $\operatorname{Age}(\text { years })^{d}$ & $28.9 \pm 7.4^{\mathrm{a}}$ & $35.7 \pm 10.4^{b}$ & $37.9 \pm 10.0^{c}$ & $<0.0001$ \\
\hline $\operatorname{BMI}\left(\mathrm{Kg} / \mathrm{m}^{2}\right)^{\mathrm{d}}$ & $22.2 \pm 1.8^{\mathrm{a}}$ & $31.4 \pm 4.2^{\mathrm{b}}$ & $34.3 \pm 4.9^{c}$ & $<0.0001$ \\
\hline Waist circumference $(\mathrm{cm})^{\mathrm{e}}$ & $74.7 \pm 5.7^{\mathrm{a}}$ & $97.8 \pm 10.8^{b}$ & $109.0 \pm 11.9^{\mathrm{c}}$ & $<0.0001$ \\
\hline Fat mass $(\mathbf{k g})^{\mathrm{d}}$ & $14.54 \pm 4.25^{\mathrm{a}}$ & $31.30 \pm 9.01^{b}$ & $36.52 \pm 10.46^{\mathrm{c}}$ & $<0.0001$ \\
\hline Lean mass $(\mathbf{k g})^{\mathrm{d}}$ & $48.93 \pm 8.94^{\mathrm{a}}$ & $57.47 \pm 11.11^{b}$ & $65.33 \pm 12.13^{\mathrm{c}}$ & $<0.0001$ \\
\hline Systolic blood pressure $(\mathbf{m m H g})^{d}$ & $115.9 \pm 9.8^{\mathrm{a}}$ & $119.9 \pm 9.0^{\mathrm{b}}$ & $130.1 \pm 10.6^{\mathrm{c}}$ & $<0.0001$ \\
\hline Diastolic blood pressure $(\mathbf{m m H g})^{d}$ & $74.0 \pm 9.9^{\mathrm{a}}$ & $77.7 \pm 7.7^{\mathrm{a}}$ & $83.5 \pm 9.5^{b}$ & $<0.0001$ \\
\hline Fasting glucose $(\mathrm{mmol} / \mathrm{L})^{\mathrm{d}, \mathrm{g}}$ & $5.8 \pm 1.3^{\mathrm{a}}$ & $5.4 \pm 0.5^{b}$ & $6.1 \pm 1.1^{\mathrm{c}}$ & 0.002 \\
\hline Fasting insulin $(\rho \mathrm{mol} / \mathrm{L})^{\mathrm{d}, \mathrm{f}}$ & $48.7 \pm 17.1^{\mathrm{a}}$ & $86.1 \pm 56.3^{b}$ & $133.1 \pm 72.3^{\mathrm{c}}$ & $<0.0001$ \\
\hline HOMA-IR ${ }^{\mathrm{d}, \mathrm{f}}$ & $1.84 \pm 0.94^{\mathrm{a}}$ & $2.98 \pm 1.77^{\mathrm{b}}$ & $5.33 \pm 3.70^{\mathrm{c}}$ & $<0.0001$ \\
\hline Total-C (mmol/L) ${ }^{d}$ & $4.13 \pm 0.67^{\mathrm{a}}$ & $4.57 \pm 1.00^{\mathrm{b}}$ & $4.84 \pm 1.14^{b}$ & 0.02 \\
\hline LDL-C (mmol/L $)^{d}$ & $2.52 \pm 0.70$ & $2.81 \pm 0.91$ & $2.99 \pm 1.23$ & 0.29 \\
\hline HDL-C $(\mathrm{mmol} / \mathrm{L})^{\mathrm{d}, \mathrm{f}}$ & $1.60 \pm 0.45^{\mathrm{a}}$ & $1.32 \pm 0.30^{\mathrm{b}}$ & $0.99 \pm 0.24^{\mathrm{c}}$ & $<0.0001$ \\
\hline $\mathrm{TG}(\mathrm{mmol} / \mathrm{L})^{\mathrm{d}, \mathrm{g}}$ & $0.77 \pm 0.31^{\mathrm{a}}$ & $1.15 \pm 0.56^{\mathrm{b}}$ & $2.16 \pm 1.21^{\mathrm{c}}$ & $<0.0001$ \\
\hline
\end{tabular}

Values are means $\pm \mathrm{SD} . * \mathrm{P}<0.05$

a,b,c Represents the differences between each group using GLM models

${ }^{\mathrm{d}} \mathrm{P}$ Values are adjusted for age and sex. eP Values are adjusted for age, sex and BMI

fValues are $\log 10$-transformed

gValues are inverse-transformed

${ }^{x} \mathrm{P}$ value for the difference between each groups

Ov/Ob: Overweight/obese

NW: Normal weight

Table 2. BCAA levels according to metabolic syndrome and obesity status.

\begin{tabular}{|l|c|c|c|}
\hline & Normal weight $(\mathbf{n = 6 5})$ & Overweight/obese (n=83) & Overweight/obese (n=46) \\
\hline Valine $(\boldsymbol{\mu M} / \mathbf{L})$ & $205.4 \pm 43.6^{\mathrm{a}}$ & $239.1 \pm 45.6^{\mathrm{b}}$ & $262.2 \pm 56.3^{\mathrm{c}}$ \\
\hline Leucine $(\boldsymbol{\mu M} / \mathbf{L})$ & $139.5 \pm 30.4^{\mathrm{a}}$ & $148.5 \pm 29.7^{\mathrm{b}}$ & $163.3 \pm 30.8^{\mathrm{c}}$ \\
\hline Isoleucine $(\boldsymbol{\mu M} / \mathbf{L})$ & $69.0 \pm 14.4^{\mathrm{a}}$ & $73.3 \pm 15.6^{\mathrm{b}}$ & $82.1 \pm 15.6^{\mathrm{c}}$ \\
\hline Total BCAAs $(\boldsymbol{\mu M} / \mathbf{L})^{\mathbf{e}}$ & $413.8 \pm 83.5^{\mathrm{a}}$ & $460.8 \pm 83.4^{\mathrm{b}}$ & $<0.0001$ \\
\hline
\end{tabular}

Values are means $\pm \mathrm{SD} * \mathrm{P}<0.05$

a,b,c Represents the differences between each group using GLM models

${ }^{\mathrm{d}} \mathrm{P}$ value for the difference between each groups

${ }^{\mathrm{e}}$ Total $\mathrm{BCAA}=\sum$ Valine, leucine, isoleucine

levels are associated with several metabolic conditions such as obesity, MetS, IR and T2DM $[5,17,18]$. The aim of this study was to investigate the association between plasma BCAA levels, obesity and MetS status.

Abdominal obesity is one of the MetS feature. However, all obese individuals do not have MetS [19,20]. Knowing this, it is interesting to see to what extent BCAA levels are associated with obesity and MetS status. The correlation of all three BCAAs with different CVD risk factors among overweight/obese with or without MetS and normal weight individuals has been investigated. It has been known for some time that obesity is accompanied with changes in circulating levels of BCAAs [21,22].

In a study on rodents, She et al. showed that BCAA serum concentrations were significantly higher among obese rodents than among lean ones [23]. In a human trial, Lackey et al. detected an increase of BCAA concentrations among obese subjects in comparison to lean individuals [24]. In the present study, significant correlations between $\mathrm{WC}$ and isoleucine were seen among overweight/obese subjects with and without MetS, the same association was only observed among overweight/obese subjects without MetS as far as leucine, valine and total BCAAs levels are concerned. BCAA levels were higher among overweight/obese with MetS than without MetS. In the present study, an increase of leucine, isoleucine and valine was observed among overweight/obese individuals compared to normal weight individuals. When MetS status is considered, overweight/obese individuals with MetS have a higher amount of each BCAA compared to overweight/ obese participants without MetS. In a study by Serralde-Zuniga et al., there was an increase in serum BCAA concentrations among subjects with MetS relative to subjects without MetS [25]. This shows that overweight/obese subjects have a higher amount of circulating 
Table 3. Partial correlations between cardiometabolic variables and BCAAs.

\begin{tabular}{|c|c|c|c|c|c|c|c|c|c|c|c|c|c|}
\hline & & \multicolumn{3}{|c|}{ Leucine } & \multicolumn{3}{|c|}{ Isoleucine } & \multicolumn{3}{|c|}{ Valine } & \multicolumn{3}{|c|}{ Total BCAAs } \\
\hline & & \multicolumn{2}{|c|}{ MetS- } & \multirow{2}{*}{$\begin{array}{l}\text { MetS+ } \\
\text { Ov/Ob } \\
(n=46)\end{array}$} & \multicolumn{2}{|c|}{ MetS- } & \multirow{2}{*}{$\begin{array}{l}\text { MetS+ } \\
\begin{array}{l}\text { Ov/Ob } \\
(n=46)\end{array}\end{array}$} & \multicolumn{2}{|c|}{ MetS- } & \multirow{2}{*}{$\begin{array}{l}\text { MetS+ } \\
\text { Ov/Ob } \\
(n=46)\end{array}$} & \multicolumn{2}{|c|}{ MetS- } & \multirow{2}{*}{$\begin{array}{l}\text { MetS+ } \\
\begin{array}{l}\text { Ov/Ob } \\
(n=46)\end{array}\end{array}$} \\
\hline & & $N W(n=65)$ & $\begin{array}{l}\text { Ov/Ob } \\
(n=83)\end{array}$ & & NW $(n=65)$ & $\begin{array}{l}\text { Ov/Ob } \\
(n=83)\end{array}$ & & $N W(n=65)$ & $\begin{array}{l}\text { Ov/Ob } \\
(n=83)\end{array}$ & & NW (n=65) & $\begin{array}{l}\text { Ov/Ob } \\
(n=83)\end{array}$ & \\
\hline \multirow{2}{*}{ WC } & $\mathrm{r}$ & 0.07 & 0.37 & 0.23 & -0.06 & 0.31 & 0.34 & -0.08 & 0.29 & 0.14 & -0.03 & 0.35 & 0.21 \\
\hline & $\mathrm{p}$ & 0.57 & 0.0008 & 0.13 & 0.63 & 0.004 & 0.02 & 0.53 & 0.009 & 0.38 & 0.81 & 0.002 & 0.16 \\
\hline \multirow{2}{*}{ Total-C } & $\mathrm{r}$ & 0.0005 & 0.02 & 0.13 & -0.02 & -0.14 & -0.19 & -0.15 & 0.0008 & -0.1 & -0.09 & -0.017 & -0.14 \\
\hline & $\mathrm{p}$ & 0.99 & 0.85 & 0.39 & 0.86 & 0.23 & 0.22 & 0.26 & 0.99 & 0.51 & 0.51 & 0.87 & 0.39 \\
\hline \multirow{2}{*}{ TG } & $\mathrm{r}$ & -0.06 & 0.16 & 0.08 & -0.08 & 0.17 & 0.2 & 0.05 & 0.08 & 0.03 & -0.007 & 0.13 & 0.08 \\
\hline & $\mathrm{p}$ & 0.66 & 0.15 & 0.61 & 0.56 & 0.14 & 0.2 & 0.73 & 0.49 & 0.84 & 0.95 & 0.23 & 0.62 \\
\hline \multirow{2}{*}{ HDL-C } & $\mathrm{r}$ & 0.22 & 0.01 & 0.1 & 0.28 & 0.003 & -0.04 & 0.14 & 0.1 & 0.15 & 0.2 & 0.065 & 0.12 \\
\hline & $\mathrm{p}$ & 0.09 & 0.87 & 0.53 & 0.03 & 0.98 & 0.79 & 0.27 & 0.36 & 0.34 & 0.11 & 0.56 & 0.44 \\
\hline \multirow{2}{*}{ LDL-C } & $\mathrm{r}$ & -0.11 & 0.001 & -0.21 & -0.17 & -0.14 & -0.32 & -0.22 & -0.07 & -0.17 & -0.19 & -0.06 & -0.23 \\
\hline & $\mathrm{p}$ & 0.37 & 0.99 & 0.18 & 0.17 & 0.22 & 0.04 & 0.09 & 0.56 & 0.27 & 0.14 & 0.57 & 0.14 \\
\hline \multirow{2}{*}{ Glucose } & $\mathrm{r}$ & -0.05 & 0.12 & 0.36 & 0.04 & 0.18 & 0.35 & -0.08 & 0.08 & 0.17 & -0.05 & 0.12 & 0.28 \\
\hline & $\mathrm{p}$ & 0.7 & 0.28 & 0.02 & 0.77 & 0.12 & 0.02 & 0.55 & 0.48 & 0.27 & 0.68 & 0.28 & 0.07 \\
\hline \multirow{2}{*}{ Insulin } & $\mathrm{r}$ & -0.03 & 0.19 & 0.17 & 0.1 & 0.21 & 0.24 & 0.18 & 0.13 & 0.18 & 0.11 & 0.18 & 0.21 \\
\hline & $\mathrm{p}$ & 0.81 & 0.09 & 0.27 & 0.43 & 0.06 & 0.12 & 0.16 & 0.25 & 0.26 & 0.4 & 0.11 & 0.18 \\
\hline \multirow{2}{*}{ SBP } & $\mathrm{r}$ & 0.03 & 0.01 & 0.03 & 0.02 & 0.08 & 0.06 & 0.009 & 0.06 & 0.005 & 0.02 & 0.05 & 0.02 \\
\hline & $\mathrm{p}$ & 0.79 & 0.91 & 0.86 & 0.86 & 0.47 & 0.69 & 0.94 & 0.63 & 0.97 & 0.87 & 0.65 & 0.89 \\
\hline \multirow{2}{*}{ DBP } & $\mathrm{r}$ & 0.21 & 0.024 & 0.003 & 0.34 & -0.08 & -0.05 & 0.2 & -0.04 & 0.04 & 0.25 & -0.03 & 0.02 \\
\hline & $\mathrm{p}$ & 0.096 & 0.83 & 0.99 & 0.007 & 0.47 & 0.74 & 0.11 & 0.75 & 0.8 & 0.05 & 0.81 & 0.9 \\
\hline \multirow{2}{*}{ HOMA-IR } & $\mathrm{r}$ & -0.06 & 0.022 & 0.24 & 0.16 & 0.25 & 0.31 & 0.13 & 0.15 & 0.2 & 0.09 & 0.21 & 0.25 \\
\hline & $\mathrm{p}$ & 0.95 & 0.05 & 0.11 & 0.36 & 0.02 & 0.04 & 0.3 & 0.18 & 0.18 & 0.47 & 0.05 & 0.09 \\
\hline
\end{tabular}

Ov/Ob: Overweight/Obese; NW: Normal Weight

BCAAs than lean individuals and that MetS is associated with a further increase of BCAA levels. In the present study, the same phenomenon is observed. Moreover, when analysing each BCAA independently in association with WC, it seems that isoleucine is associated with obesity irrespectively of the MetS status whereas valine and leucine are associated with obesity but not with MetS status.

There was a positive and significant association of isoleucine levels and HOMA-IR among overweight/obese individuals irrespective of the MetS status. No association was seen for normal weight participants. Leucine and the combination of the 3 BCAAs were correlated to HOMA-IR but only among overweight/obese subjects without MetS. For valine levels, there was no association with HOMA-IR. IR is a physiological condition in which cells fail to respond to the normal action of insulin [26]. The body produces insulin to maintain glucose levels, but cells become resistant to insulin and are unable to use it as effectively [27]. Beta cells in the pancreas subsequently increase their production of insulin, further contributing to increased insulin levels [27]. IR is a common feature of obesity and an important risk factor for the development of T2DM, MetS and CVD [28]. Studies on BCAA supplementation in obese and normal weight animals and humans indicated that circulating amino acids may directly promote IR [5,29]. In fact, in obese and IR individuals, an increase of plasma BCAA levels is often observed [30]. More interestingly, weight loss among obese subjects triggers an intense decline in circulating BCAA levels [31], and improves insulin sensitivity [32,33]. In the current study, when analysing different groups, even though HOMA-IR index was higher among overweight/obese people with MetS, overweight/obese participants without MetS can also be considered as being IR. When analysing the effect of each BCAA, isoleucine seems to be correlated to HOMA-IR among overweight/obeseirrespective of the MetS status. On the other hand, the association of leucine with HOMA-IR is only significant among overweight/obese without MetS.

An increase of HOMA-IR, along with an increase of each BCAA plasma levels among overweight/obese people was observed in the present study. It is well documented that the increase of BCAA levels in obese/overweight individuals is associated with a degradation of insulin sensitivity [5,34]. The present study shows that leucine and isoleucine but not valine seems to be linked to IR among overweight/ obese individuals without MetS. When MetS is taken into account, this association remains significant only for isoleucine. With further analyses these two BCAAs could be used as markers of early (leucine) and later (isoleucine) stages of IR and also as a predictor of MetS in obese people (isoleucine). Monitoring changes in leucine and isoleucine circulating levels may provide insights into the initiation of metabolic diseases such as T2DM. Metabolic diseases are often present several years before becoming clinically apparent. For example, by the time relative insulin deficiency manifests itself as hyperglycemia and T2DM diagnosis is made, significant pancreatic alpha-cell insufficiency has already occurred [35]. Clinical predictors such as BMI or blood glucose levels can help for the prediction of T2DM. Unfortunately, 
they are often used when the disease is at an advanced stage [36]. A study in young Finnish adults by Wurtz et al. demonstrated on one hand that the metabolic signature of IR was modulated by obesity and on the other hand that plasma BCAA levels could be used as markers of early stage of IR because the metabolic profile of the participants was not deteriorated enough [37]. Finally, a study led among children and adolescent suggested that changes in BCAA levels might be an early manifestation of metabolic disorders coming with overeating [38]. This really underlines the fact that plasma BCAA circulating levels can predict the future development of metabolic diseases.

There was a correlation between leucine, isoleucine and fasting glucose levels but only among obese/overweight individuals with MetS. It seems that when we consider total BCAAs this association is no longer significant. In this study, increased fasting glucose levels were seen with obesity. Obese/overweight subjects had a higher blood glucose levels than normal weight individuals, and MetS increased this level. However, the obese/overweight participants with MetS had impaired fasting glucose $(>5.6 \mathrm{mmol} / \mathrm{L})$. This may be an explanation why no association was observed between BCAAs and plasma glucose levels in obese/overweight group without MetS. Indeed, their metabolic status is probably not deteriorated enough to alter or affect fasting glucose levels. This suggests that plasma BCAA concentrations might serve as a better indicator of impaired IR in pre-diabetic state than plasma glucose levels.

In conclusion, results of the present study suggest that plasma BCAA levels could be used as a predictor for future metabolic diseases among obese/overweight people. However, to confirm this hypothesis, longitudinal study must be performed. It is also important to separate the action of each BCAA because they do not seem to be all associated to the same extent with cardiometabolic risk factors.

\section{Acknowledgements}

This research would not have been possible without the excellent collaboration of all the participants. We would like to thank Marie-Eve Bouchard, Steve Amireault, Diane Drolet, and Dominique Beaulieu for their involvement in the recruitment of the subjects, study coordination, and data collection and VéroniqueGarneau for the statistical analyses. We would also like to thank Chenomx Inc. (Edmonton, Canada) who performed the mass spectrometry analyses to obtain plasma BCAA levels.

\section{Funding}

This study was supported by a grant from the Canadian Institutes of Health Research (CIHR). M.C.V. holds a Tier 1 Canada Research Chair in Genomics Applied to Nutrition and Health.

\section{Authors contribution}

LP and MCV contributed to the conception and design of this study. BAN and VG participated to statistical analyses ANB, VG, FG, $\mathrm{OB}, \mathrm{LP}$ and MVC participated to the interpretation of data. ANB and FG drafted the manuscript. VG, OB and LP critically revised the article for intellectual content. All authors approved the final manuscript. ANB and VG are responsible for the integrity of the work as whole.

\section{References}

1. Expert Panel on Detection, Evaluation, and Treatment of High Blood Cholesterol in Adults (2001) Executive Summary of The Third Report of The National Cholesterol Education Program (NCEP) Expert Panel on Detection, Evaluation, And Treatment of High Blood Cholesterol In Adults (Adult Treatment Panel III). JAMA 285: 2486-2497. [Crossref]
2. Hedley AA, Ogden CL, Johnson CL, Carroll MD, Curtin LR, et al. (2004) Prevalence of overweight and obesity among US children, adolescents, and adults, 1999-2002. JAMA 291: 2847-2850. [Crossref]

3. Sowers JR (2003) Obesity as a cardiovascular risk factor. Am J Med 115 Suppl 8A: 37S-41S. [Crossref]

4. Wahl S, Yu Z, Kleber M, Singmann P, Holzapfel C, et al. (2012) Childhood obesity is associated with changes in the serum metabolite profile. Obes Facts 5: 660-670. [Crossref]

5. Newgard CB, An J, Bain JR, Muehlbauer MJ, Stevens RD, et al. (2009) A branchedchain amino acid-related metabolic signature that differentiates obese and lean humans and contributes to insulin resistance. Cell Metab 9: 311-326. [Crossref]

6. Huang Y, Zhou M, Sun H, Wang Y (2011) Branched-chain amino acid metabolism in heart disease: an epiphenomenon or a real culprit? Cardiovasc Res 90: 220-223. [Crossref]

7. Layman DK (2003) The role of leucine in weight loss diets and glucose homeostasis. $J$ Nutr 133: 261S-267S. [Crossref]

8. Matsuoka S, Tamura A, Nakagawara H, Moriyama M (2014) Improvement in the nutritional status and clinical conditions of patients with liver failure using a liver diet combined with a branched chain amino acids-enriched elemental diet. Hepatogastroenterology 61: 1308-1312. [Crossref]

9. Nakaya Y, Okita K, Suzuki K, Moriwaki H, Kato A, et al. (2007) BCAA-enriched snack improves nutritional state of cirrhosis. Nutrition 23: 113-120. [Crossref]

10. Chotechuang N, Azzout-Marniche D, Bos C, Chaumontet C, Gausserès N, et al. (2009) mTOR, AMPK, and GCN2 coordinate the adaptation of hepatic energy metabolic pathways in response to protein intake in the rat. Am J Physiol Endocrinol Metab 297: E1313-1323. [Crossref]

11. Saha AK1, Xu XJ, Lawson E, Deoliveira R, Brandon AE, et al. (2010) Downregulation of AMPK accompanies leucine- and glucose- induced increases in protein synthesis and insulin resistance in rat skeletal muscle. Diabetes 59: 2426-2434. [Crossref]

12. Yang R, Dong J, Zhao H, Li H, Guo H, et al. (2014) Association of branched-chain amino acids with carotid intima-media thickness and coronary artery disease risk factors. PLoS One 9: e99598. [Crossref]

13. Paradis AM, Pérusse L, Godin G, Vohl MC (2008) Validity of a self-reported measure of familial history of obesity. Nutr $J$ 7: 27. [Crossref]

14. Albers JJ, Warnick GR, Wiebe D, King P, Steiner P, et al. (1978) Multi-laboratory comparison of three heparin-Mn2+ precipitation procedures for estimating cholesterol in high-density lipoprotein. Clin Chem 24: 853-856. [Crossref]

15. Kubo N (2002) Evaluation of LDL-cholesterol measurement. Rinsho Byori 50: 242 247. [Crossref]

16. Matthews DR, Hosker JP, Rudenski AS, Naylor BA, Treacher DF, et al. (1985) Homeostasis model assessment: insulin resistance and beta-cell function from fasting plasma glucose and insulin concentrations in man. Diabetologia 28: 412-419. [Crossref]

17. Layman DK, Walker DA (2006) Potential importance of leucine in treatment of obesity and the metabolic syndrome. J Nutr 136: 319S-23S. [Crossref]

18. Wang TJ, Larson MG, Vasan RS, Cheng S, Rhee EP, et al. (2011) Metabolite profiles and the risk of developing diabetes. Nat Med 17: 448-453. [Crossref]

19. Fernandez-Real JM, Menendez JA, Moreno-Navarrete JM, Blüher M, Vazquez-Martin A, et al. (2010) Extracellular fatty acid synthase: a possible surrogate biomarker of insulin resistance. Diabetes 59: 1506-1511. [Crossref]

20. Karelis AD, St-Pierre DH, Conus F, Rabasa-Lhoret R, Poehlman ET (2004) Metabolic and body composition factors in subgroups of obesity: what do we know? J Clin Endocrinol Metab 89: 2569-2575. [Crossref]

21. Caballero B, Finer N, Wurtman RJ (1988) Plasma amino acids and insulin levels in obesity: response to carbohydrate intake and tryptophan supplements. Metabolism 37: 672-676. [Crossref]

22. Tai ES, Tan ML, Stevens RD, Low YL, Muehlbauer MJ, et al. (2010) Insulin resistance is associated with a metabolic profile of altered protein metabolism in Chinese and Asian-Indian men. Diabetologia 53: 757-767. [Crossref]

23. She P, Olson KC, Kadota Y, Inukai A, Shimomura Y, et al. (2013) Leucine and protein metabolism in obese Zucker rats. PLoS One 8: e59443. [Crossref]

24. Lackey DE, Lynch CJ, Olson KC, Mostaedi R, Ali M, et al. (2013) Regulation of adipose branched-chain amino acid catabolism enzyme expression and cross-adipose 
amino acid flux in human obesity. Am J Physiol Endocrinol Metab 304: E1175-E1187. [Crossref]

25. Serralde-Zúñiga AE1, Guevara-Cruz M, Tovar AR, Herrera-Hernández MF, Noriega LG, et al. (2014) Omental adipose tissue gene expression, gene variants, branched-chain amino acids, and their relationship with metabolic syndrome and insulin resistance in humans. Genes Nutr 9: 431. [Crossref]

26. Bonora E, Kiechl S, Willeit J, Oberhollenzer F, Egger G, et al. (1998) Prevalence of insulin resistance in metabolic disorders: the Bruneck Study. Diabetes 47: 1643-1649. [Crossref]

27. Lewis GF, Carpentier A, Adeli K, Giacca A (2002) Disordered fat storage and mobilization in the pathogenesis of insulin resistance and type 2 diabetes. Endocr Rev 23: 201-229. [Crossref]

28. Grundy SM, Brewer HB Jr, Cleeman JI, Smith SC Jr, Lenfant C (2004) Definition of metabolic syndrome: Report of the National Heart, Lung, and Blood Institute/American Heart Association conference on scientific issues related to definition. Circulation 109: 433-438. [Crossref]

29. Krebs M, Krssak M, Bernroider E, Anderwald C, Brehm A, et al. (2002) Mechanism of amino acid-induced skeletal muscle insulin resistance in humans. Diabetes 51: 599605. [Crossref]

30. Pietiläinen KH, Naukkarinen J, Rissanen A, Saharinen J, Ellonen P, et al. (2008) Global transcript profiles of fat in monozygotic twins discordant for BMI: pathways behind acquired obesity. PLoS Med 5: e51. [Crossref]

31. Shah SH, Crosslin DR, Haynes CS, Nelson S, Turer CB, et al. (2012) Branched-chain amino acid levels are associated with improvement in insulin resistance with weight loss. Diabetologia 55: 321-330. [Crossref]

32. Magkos F, Bradley D, Schweitzer GG, Finck BN, Eagon JC, et al. (2013) Effect of Roux-en-Y gastric bypass and laparoscopic adjustable gastric banding on branchedchain amino acid metabolism. Diabetes 62: 2757-2761. [Crossref]

33. Shah AA, Craig DM, Sebek JK, Haynes C, Stevens RC, et al. (2012) Metabolic profiles predict adverse events after coronary artery bypass grafting. J Thorac Cardiovasc Surg 143: 873-878. [Crossref]

34. Huffman KM1, Shah SH, Stevens RD, Bain JR, Muehlbauer M, et al. (2009) Relationships between circulating metabolic intermediates and insulin action in overweight to obese, inactive men and women. Diabetes Care32: 1678-1683. [Crossref]

35. Tabák AG, Jokela M, Akbaraly TN, Brunner EJ, Kivimäki M, et al. (2009) Trajectories of glycaemia, insulin sensitivity, and insulin secretion before diagnosis of type 2 diabetes: an analysis from the Whitehall II study. Lancet 373: 2215-2221. [Crossref]

36. Wilson PW, Meigs JB, Sullivan L, Fox CS, Nathan DM, et al. (2007) Prediction of incident diabetes mellitus in middle-aged adults: the Framingham Offspring Study. Arch Intern Med 167: 1068-1074. [Crossref]

37. Würtz P, Havulinna AS, Soininen P, Tynkkynen T, Prieto-Merino D, et al. (2015) Metabolite profiling and cardiovascular event risk: a prospective study of 3 populationbased cohorts. Circulation 131: 774-785. [Crossref]

38. McCormack SE, Shaham O, McCarthy MA, Deik AA, Wang TJ, et al. (2013) Circulating branched-chain amino acid concentrations are associated with obesity and future insulin resistance in children and adolescents. Pediatr Obes 8: 52-61. [Crossref]

Copyright: ${ }^{0} 2015$ Allam-Ndoul B. This is an open-access article distributed under the terms of the Creative Commons Attribution License, which permits unrestricted use, distribution, and reproduction in any medium, provided the original author and source are credited. 